\title{
Análise comparativa das relações entre ensino e aprendizagem por professores e alunos
}

\author{
Andréia Osti \\ Rosely Palermo Brenelli
}

\begin{abstract}
Resumo
Esta pesquisa identificou e comparou as representações de professores e alunos sobre o processo de ensino e aprendizagem. Objetivouse verificar em quais aspectos as representações desses sujeitos se correspondem e se elas se diferenciam entre alunos com alto e baixo desempenho acadêmico. A coleta de dados foi organizada por meio de uma entrevista semiestruturada. Participaram deste estudo vinte professores e quarenta alunos do $5^{\circ}$ ano do Ensino Fundamental da rede pública municipal da região metropolitana de Campinas. As respostas das entrevistas foram categorizadas e analisadas através do teste exato de Fisher, Qui-Quadrado e Proporções. Os resultados demonstraram que professores e alunos apresentam uma visão parcial dos fatores envolvidos no processo de ensino e aprendizagem. A aprendizagem é compreendida como um processo individual e não social. Professores e alunos com alto desempenho representam positivamente o ambiente da sala de aula, diferentemente dos alunos com baixo desempenho acadêmico.
\end{abstract}

Palavras-chave: Representação, aprendizagem, rendimento escolar.

\section{Comparative analysis of the relationship between teaching and learning from teachers's and students's view}

\begin{abstract}
In this research we identified and compared the representations of teachers and students on teaching and learning. The objective was to determine which aspects of these representations correspond to subjects and if they differ between students with high and low academic performance. Data collection was organized through a semi-structured interview. The study included twenty teachers and forty students in the 5th year of elementary school municipal public metropolitan region of Campinas. The responses from the interviews were categorized and analyzed by using the Fisher exact test, chi-square and Proportions. The results show that teachers and students present a partial view of the factors involved in teaching and learning. The learning process is understood as an individual and social factor. Teachers and students with high performance positively represent the environment of the classroom, unlike the students with lower academic performance.
\end{abstract}

Keywords: Representation, learning, academic achievement.

\section{Análisis comparativo de las relaciones entre la enseñanza y el aprendizaje por profesores y alumnos}

\begin{abstract}
Resumen
Esta investigación identificó y comparó las representaciones de profesores y alumnos sobre el proceso de enseñanza y aprendizaje. El estudio tuvo el objetivo de verificar en cuáles aspectos las representaciones de estos sujetos se corresponden y si ellas son diferentes entre alumnos con alto y bajo rendimiento académico. La recolección de datos se realizó por medio de una entrevista semi-estructurada. Participaron de este estudio veinte profesores y cuarenta alumnos del $5^{\circ}$ año de la Enseñanza Fundamental de la red pública municipal de la región metropolitana de Campinas. Las respuestas de las entrevistas fueron categorizadas y analizadas a través del test exacto de Fisher, Chi-Cuadrado y Proporciones. Los resultados demostraron que profesores y alumnos presentan una visión parcial de los factores involucrados en el proceso de enseñanza y aprendizaje. El aprendizaje es comprendido como un proceso individual y no social. Profesores y alumnos con alto rendimiento representan positivamente el ambiente de la clase, diferente de los alumnos con bajo rendimiento académico.
\end{abstract}

Palabras clave: Representación, aprendizaje, rendimiento escolar. 


\section{Introdução}

Todas as formas de interação entre alunos e professores formam uma história constituinte de sua relação com o saber. No decorrer do processo educativo as representações sobre ensino e aprendizagem são construídas num meio permeado tanto pelo cognitivo quanto pelo afetivo. A escola além de ser um ambiente dinâmico e diversificado, promotor de conhecimento, também é repleto de interações, constituindo-se um local de socialização entre os indivíduos. Nessa perspectiva, destacamos a necessidade de se analisar as representações de professores e alunos construídas e transformadas nesse contexto.

Considerando a sala de aula como um espaço de interações simultâneas entre professores e alunos, podemos dizer que a cada momento e em cada ação desencadeada por esses sujeitos são mobilizados conhecimentos e afetos. Esses afetos podem ser percebidos por alunos e professores como positivos ou negativos, dependendo da qualidade das relações estabelecidas em sala.

A representação do professor sobre seu aluno funciona não só como um filtro, direcionando o docente a interpretar o que os estudantes fazem, mas também como um meio de lidar com as aprendizagens e a reagir de forma diferente ante seus progressos e dificuldades. Coll e Miras (2001) também acreditam que a percepção dos alunos sobre seu professor condiciona em grande parte a interpretação deles de tudo aquilo que o docente diz e faz, podendo em alguns casos, modificar o comportamento do professor na direção das expectativas associadas a essa percepção. O reverso também é verdadeiro, pois alunos podem modificar seu comportamento na direção da expectativa do professor.

Nesse sentido, segundo Gilly (2001), o estudo das representações é um instrumento de grande utilidade para a Educação, pois contribui para a compreensão do que ocorre em sala de aula, permitindo investigar a interação educativa e os mecanismos de aprendizagem. Estudando o imaginário dentro da relação pedagógica, Postic (1989) ressalta que a criança aprende a se comportar em função das expectativas do professor em relação às respostas cognitivas e aos tipos de conduta por ele aceitas, segundo sua tolerância ou severidade.

Posto essas considerações, é possível perceber como as representações podem vir a interferir na prática educativa. Segundo Arruda (2004) ao nos comunicarmos com outra pessoa ou grupo revelamos nossas representações e essas podem (ou não) ser misturadas às representações do outro, contribuindo para uma organização mental mais elaborada. Pensando na dinâmica da sala de aula, acreditamos que esse movimento de formação de representações é sem dúvida importante ao processo de ensino e aprendizagem, pois as informações, os valores e as crenças provindas do senso comum e do ambiente escolar participam da mediação social. "Cada vez que um saber é gerado e comunicado - torna-se parte da vida coletiva" (Rangel, 2004, p. 14).

Mediante o exposto, ao tentar descrever uma sala de aula, podemos afirmar que esta é composta por carteiras, cadeiras, a mesa do professor, lousa, giz, cesto de lixo, armários, cartazes, quadros. Mas é tão somente um ambiente vazio se não houver nem alunos nem professores. O que faz uma sala de aula existir não é apenas seu espaço físico, mas a existência e a convivência de pessoas. São esses indivíduos que dão vida à ela e é pensando neles e nas relações construídas neste espaço, que construímos a temática desse trabalho. Buscou-se verificar em quais aspectos as representações de professores e alunos sobre o processo de ensino e aprendizagem se correspondem e se elas se diferenciam entre alunos com alto e baixo desempenho acadêmico.

A teoria das representações sociais fornece subsídios para melhor compreender as concepções acerca do ambiente de ensino e aprendizagem. Um de seus pressupostos é que a imagem construída pelos professores e alunos sobre o ambiente da sala de aula, acaba sendo vinculada à sua própria experiência de aprendizagem. De acordo com Moscovici (2005) e Dotta (2006) o universo do indivíduo é formado por uma série de relacionamentos e interações impregnadas de representações, portanto elas constituem uma das vias de apreensão do mundo concreto.

O comportamento do professor é em grande parte resultado de seu próprio pensamento (Sadalla,1997). Desta forma, todos os professores possuem alguma teoria pessoal sobre seus alunos, a qual é freqüentemente expressa como princípio de prática, acabando por influenciar suas escolhas pedagógicas. Em relação ao estudante, Guimarães (2004) verificou em alunos com vinculação com as pessoas do ambiente escolar e com sentimentos de pertencer, maior sucesso nas atividades e aprendizagem. Em consonância, Ladd, Buhs e Troop (2002) afirma que com o avanço da escolaridade os alunos podem experienciar relações positivas ou negativas com colegas e professores no ambiente escolar.

Ao vivenciar relações positivas os estudantes tendem a se sentir mais confortáveis e seguros. Por outro lado, quando vivenciam relações negativas, podem desenvolver atitudes de rejeição em relação à escola, acarretando assim uma desvalorização pessoal e baixo rendimento relacionado à aprendizagem cognitiva, social ou emocional. Isso nos leva a refletir o quanto as relações vinculares entre alunos e professores são importantes durante todo o processo escolar, pois tanto favorecem quanto inibem o interesse pela aprendizagem e a adaptação escolar.

Alguns autores como Almeida e Placco (2004), Santos, Rhueda e Bartholomeu (2006), consideram os professores significantes para o desenvolvimento social das crianças, pois podem criar um ambiente tanto acolhedor quanto tenso. Isso pode suscitar a emergência de sentimentos e / ou ações condenáveis por parte dos alunos. Segundo Rey (1995), compreender os problemas vividos em sala de aula requer cautela uma vez que a relação professor $x$ aluno não pode ser reduzida ao processo cognitivo, pois há também a dimensão afetiva nessa interação.

Consideramos que a aprendizagem pressupõe uma relação entre duas ou mais pessoas, ou entre uma pessoa e um objeto. Nesse campo também se estabelecem relações afetivas que fortalecem (ou não) vínculos entre pro- 
fessores e alunos. É essencial reconhecer a afetividade do aluno como uma dimensão inseparável e indissociável da inteligência, promotora do desenvolvimento. Nesse sentido é necessário ao professor ter clareza e consciência de sua própria afetividade enquanto educador.

$\mathrm{Na}$ opinião de Moscovici (2010) as representações circulam, modificam e se cristalizam incessantemente. Por isso as relações cotidianas são importantes para a compreensão de como os indivíduos, no nosso caso, alunos e professores, representam suas relações e o ambiente de convívio. É importante conhecer como alunos e professores pensam a situação de aprendizagem e de ensino, pois segundo Rubinstein (2003) nossas ações são pautadas pelas significações que lhes atribuímos, ou seja, os julgamentos que fazemos sobre as coisas de certa forma determinam nossa relação com elas.

Pensamos que tanto professores quanto alunos têm suas representações articuladas a uma visão de si, do outro e das relações entre seus pares. Essas, por sua vez, espelham os valores, desejos, sentimentos, frustrações, aspirações, marcando esses indivíduos ao mesmo tempo em que lhes asseguram um espaço nos grupos com os quais interagem.

As representações sociais articulam "elementos afetivos, mentais, sociais, integrando a cognição, a linguagem e a comunicação" (Jodelet, 1995, p. 121). Acreditamos que seu estudo deve incluir seu contexto de formação, no caso particular desta pesquisa, o contexto a ser considerado é a sala de aula. De acordo com André (1991), o estudo do cotidiano escolar é importante seja através de como a escola desempenha seu papel na forma da transmissão dos conteúdos ou na veiculação de crenças, valores e das interações.

A relevância do estudo das representações sociais no âmbito escolar se justifica pelo fato da representação se formar na prática social, refletindo os pensamentos e sentimentos despertados, formados e consolidados na experiência diária daqueles que trabalham e são servidos pela escola. Consideramos importante pesquisar alunos e professores pois como relata Gilly (2001), as situações de julgamento sobre o outro são interessantes por serem particularmente reveladoras dos aspectos mais funcionais da representação.

Seguindo essa mesma perspectiva teórica, Schiele e Boucher (2001) afirmam que as representações norteiam todas as atividades humanas, sendo elaboradas ao mesmo tempo coletiva e individualmente. Queremos com isso destacar a importância dessa teoria, pois a consideramos fundamental para a compreensão de diversos temas e áreas, sobretudo na educação, em que as interações e o contato com o outro, são inevitáveis e essenciais ao desenvolvimento do processo de ensino e aprendizagem.

Refletindo sobre o exposto, consideramos extremamente importante analisar as representações no ambiente escolar, lembrando que as relações e práticas escolares, assim como a cultura escolar, podem contribuir para a construção e reprodução de estereótipos e discriminações, seja de raça, classe social ou gênero.

\section{Método}

\section{Participantes}

Os participantes desse estudo foram 20 professores e 40 alunos (sendo 20 com baixo desempenho acadêmico e $20 \mathrm{com}$ adequado desempenho acadêmico) do $5^{\circ}$ ano do Ensino Fundamental de escolas públicas municipais da Região Metropolitana de Campinas, indicados por seus professores.

Todos os professores participantes (100\%) pertencem ao gênero feminino, apresentam idades variando entre 25 e 46 anos. Em relação à formação acadêmica, $60 \%$ possuem graduação em Pedagogia enquanto os demais ainda estão em curso. O tempo mínimo de docência nesse grupo é de cinco anos sendo todos concursados efetivos.

Em relação aos alunos podemos destacar certos aspectos predominantes: $35 \%$ do grupo com adequado desempenho acadêmico são meninos e $65 \%$ meninas. Quanto à repetência, esse grupo apresentou maior proporção de alunos sem reprovação (80\%). Dos alunos considerados com insatisfatório desempenho acadêmico $85 \%$ são meninos e 15\% meninas. Observa-se assim uma predominância nessa pesquisa quanto ao gênero. Todos os alunos com desempenho insatisfatório (100\%) apresentam histórico de repetência escolar. Desses, $65 \%$ foram reprovados uma única vez enquanto $35 \%$ tiveram duas reprovas. Em ambos os grupos a reprovação ocorreu no $3^{\circ}$ ano ou $5^{\circ}$ ano. Em relação à composição familiar, a maioria dos alunos com bom desempenho (85\%) mora com os pais, enquanto $65 \%$ dos alunos com desempenho insatisfatório mora apenas com a mãe ou avós.

\section{Instrumentos}

Foram utilizadas duas entrevistas semi-estruturadas com quinze questões abertas aplicadas aos professores e alunos visando analisar em quais aspectos as representações desses sujeitos se aproximam em relação ao ensino e aprendizagem.

\section{Procedimento de coleta}

Inicialmente a pesquisa foi submetida ao Comitê de Ética da Faculdade de Ciências Médicas da Universidade Estadual de Campinas - Unicamp tendo sido aprovada a Secretaria de Educação do Município foi contatada e solicitada permissão para a realização da pesquisa nas escolas da rede. Devidamente autorizada, a pesquisadora agendou dia e horário com as escolas para apresentar aos professores a pesquisa e os informou que ao participar da entrevista deveriam indicar cada um, dois de seus alunos (um com bom desempenho acadêmico e um com insatisfatório desempenho acadêmico). Após esse procedimento, os termos de consentimento livre e esclarecido foram entregues 
aos professores e, mediante a aceitação em participar da pesquisa, organizou-se a agenda dos os dias e os horários para a entrevista. Esta ocorreu individualmente, na própria escola, durante o horário de trabalho do professor, mais especificamente durante o HTP (hora de trabalho pedagógico), em espaço cedido pela direção.

A aplicação dos instrumentos com os alunos se iniciou pelo encaminhamento de uma carta aos pais explicando a pesquisa e pedindo a autorização dos mesmos para a coleta de dados. Após o recebimento das autorizações, foram agendados junto ao professor e coordenação os dias e horários para a aplicação dos instrumentos com os alunos. A entrevista foi realizada individualmente durante o horário de aula.

\section{Procedimento de análise dos dados}

Os resultados das entrevistas foram agrupados visando à comparação entre professores e alunos. As categorias construídas foram organizadas em cinco classes gerais: concepção sobre aprendizagem, percepção sobre o ambiente da sala de aula, experiências de aprendizagem e ambientes significativos, representação sobre alunos com dificuldades para aprender e percepção do outro.

Os dados coletados foram tratados por meio da análise de conteúdo seguindo a perspectiva de Bardin (1979). Essa técnica permite explorar as avaliações, opiniões, julgamentos e a representação do indivíduo a partir dos seus enunciados. Tem por finalidade a descrição objetiva do conteúdo manifestado na comunicação, através da linguagem expressa no conteúdo da palavra, seu aspecto individual e atual.

A análise de conteúdo se organiza em três fases, a pré-análise, a exploração do material e o tratamento dos resultados. A primeira busca sistematizar as idéias iniciais e formular hipóteses. A exploração do material consiste na codificação, categorização e quantificação das informações coletadas, sendo a mais exaustiva de todo o processo de análise. Os dados brutos são transformados, através do recorte (escolha da unidade), da enumeração (escolha das regras de contagem) e pela agregação (escolha das categorias).

Em nossa pesquisa, no momento da codificação, extraímos das falas dos sujeitos as unidades de registro e essas foram agrupadas num tema ou palavra-chave. As palavras-chave foram classificadas num conjunto por diferenciação, e reagrupadas de acordo com os critérios definidos nos objetivos da pesquisa. Neste trabalho usamos a categoria léxica, pois as palavras-chave foram reunidas, enumeradas e classificadas segundo seu sentido. Para comparar as respostas de alunos e professores utilizou-se o teste Qui-Quadrado, teste de Proporções e teste exato de Fisher. O nível de confiança utilizado nas análises comparativas foi de $95 \%$ e o software estatístico empregado foi o XLSTAT 2009.

\section{Resultados e Discussão}

Os resultados das entrevistas foram agrupados visando analisar as representações de professores e alunos. Cabe destacar que no decorrer do texto os alunos com adequado desempenho são descritos como $S$ (satisfatório) e os alunos com desempenho insatisfatório como NS (não satisfatório), termos esses utilizados na própria rede municipal onde esta pesquisa foi realizada e que servem como um referencial aos professores e coordenadores para classificar os alunos. Também incluímos, a título de exemplos, alguns protocolos com as respostas dos participantes tais como foram expressas, a fim de manter a fidedignidade dos relatos.

Ao analisar qual a concepção sobre aprendizagem a proporção de respostas para a categoria desempenho (nota) foi significativamente superior para os professores comparada à proporção de resposta para a categoria conceito (nota) dos alunos com desempenho insatisfatório (teste de proporções; $p$-valor $=0,008$ ) e dos alunos com bom desempenho (teste de proporções; p-valor<0,001). Não foi encontrada associação significativa entre a verificação da aprendizagem entre os alunos (teste exato de Fisher; $p$-valor=0,111). Apesar da diferença não ter sido estatisticamente significativa, nota-se que a maioria dos alunos relacionam a verificação da aprendizagem com o saber solucionar o exercício $(80 \%$ alunos S) e com a nota (70\% alunos NS). Para esses últimos, o resultado atingido numa prova é fator que aponta para o sucesso ou não da aprendizagem. Em suas palavras: "percebo que aprendo quando acerto o exercício", "quando tiro nota boa e vou bem na prova", "quando tem nota boa no boletim".

Para $80 \%$ dos alunos "S" o saber realizar as atividades individualmente sem contar com a ajuda da professora ou dos colegas é muito mais importante do que a nota em si: "eu aprendi quando consigo fazer a tarefa", "eu sei que aprendi depois que eu faço sozinha e não peço ajuda", "quando pego a folha e faço a lição". É possível inferir que os alunos "S" demonstram maior autonomia intelectual ao valorizarem a realização das tarefas, não se centrando apenas na nota. Entretanto, os alunos "NS" pautam-se principalmente nos resultados de seu desempenho e não nos motivos que os poderiam levar a esses.

Ao relacionarmos esses dados com a teoria das Representações Sociais, podemos afirmar que a representação de aprendizagem foi convencionalizada no momento em que o desempenho acadêmico, traduz de certa maneira, quem é esse estudante. Ter boas notas e um boletim repleto de conceitos dentro da média ou acima dela correspondem à imagem do bom aluno, enquanto não atingir média ou estar em defasagem conferem um status de mau aluno. Ela também é prescritiva pois avaliar os alunos e conferir um conceito ao seu desempenho é uma prática educacional mantida desde os primórdios da história da educação. A avaliação é uma maneira de classificar e a nota ainda é a forma mais comum de representar o histórico acadêmico.

O hábito de classificar diz respeito ao processo designado por Moscovici (2010) de ancoragem. Ancorar impli- 
ca estabelecer uma relação positiva ou negativa de acordo com a categoria estabelecida. Nesse caso, o conceito do desempenho do aluno. Por exemplo, na rede onde essa pesquisa foi realizada os conceitos "S" e "NS" correspondem respectivamente ao desempenho satisfatório e não satisfatório. Portanto, se um aluno tem " $\mathrm{S}$ " no boletim isso evidencia um desempenho adequado, por outro lado, ter "NS" significa não acompanhar os conteúdos e via de regra, estar em defasagem. Essa classificação - adequado ou insatisfatório desempenho acadêmico - configura a ancoragem.

As representações dos alunos acerca de como aprendem se interseccionam com as representações de seus professores. Observamos nas representações desses últimos que o indicador da aprendizagem de seus alunos se centra nos resultados obtidos nas avaliações e no rendimento alcançado evidenciado pela nota. Nesse sentido, o professor influencia nos alunos tanto suas idéias de aprendizagem quanto sua própria aprendizagem, pois "o ato de aprender sempre supõe uma relação com outra pessoa, a que ensina". (Kupfer, 1992, p. 84). Acreditamos que essa influência também tenha repercussão sobre a não aprendizagem dos alunos, pois a partir dessas interações e de suas experiências, esses sujeitos constroem representações sobre o mundo e sobre si mesmos.

Articulando nossos resultados com algumas correntes pedagógicas, podemos dizer que professores e alunos com baixo desempenho manifestam uma representação de ensino correspondente a uma tendência pedagógica tradicional, priorizando a exposição e a assimilação dos conteúdos. Já os alunos com desempenho satisfatório apresentam uma perspectiva mais construtivista, voltada à aprendizagem, pois o foco está em aprender, em saber fazer, ou seja, centram-se no processo de aprendizagem e não no ensino.

Em relação à categoria referente ao ambiente da sala de aula, foi encontrada associação significativa entre os professores e alunos "NS" (teste exato de Fisher; p-valor $=0,008)$. A maioria dos professores $(85 \%)$ indicou que o ambiente da sala possibilita a aprendizagem, enquanto apenas $25 \%$ dos alunos "NS" indicaram o mesmo. Não foi encontrada associação significativa entre os professores e alunos "S" (teste exato de Fisher; p-valor=1,000).

Ao comparar os alunos encontramos significância em relação à percepção do ambiente da sala de aula (teste exato de Fisher; $p$-valor=0,002). A maior parte dos alunos "S" $(90 \%)$ afirma que a sala de aula possibilita a aprendizagem, enquanto $75 \%$ dos "NS" apontam o contrário, não percebem a sala de aula como um ambiente favorável ao aprender.

Analisando mais especificamente as justificativas de professores e alunos no que concerne ao ambiente da sala de aula; $15 \%$ dos professores afirmam não terem um ambiente favorável à aprendizagem por conta do comportamento dos alunos, como a indisciplina e falta de respeito. Nos relatos dos alunos, esses apontam a "conversa" e a "bagunça" como aspectos que dificultam a aprendizagem. No entanto, também consideram a falta de atenção do professor e sua prontidão para ensinar como outra variável que implica na não aprendizagem.
Acreditamos que o processo de ensino e aprendizagem configura uma situação de comunicação na qual professores e alunos atuam como co-responsáveis. Pensando na sala de aula, podemos dizer que professores e alunos com desempenho satisfatório representam positivamente esse ambiente porque para esses a aprendizagem de certa forma se materializa, ou seja, o professor consegue ensinar. Esses alunos aprendem, portanto o ambiente sócio afetivo é favorável ao aprender. Em contrapartida, alunos com baixo desempenho não representam da mesma maneira porque não aprendem e por estarem em defasagem em relação aos conteúdos. Essas representações apontam para o valor afetivo envolvido no processo de ensino e aprendizagem.

O ponto de partida dos problemas de aprendizagem está, segundo Placco (2004), nas relações estabelecidas no interior do cotidiano escolar, pois o vínculo entre professores e alunos configura elemento essencial para a aprendizagem. Queremos com isso dizer que, embora a análise comparativa dos grupos nos forneça dados interessantes não podemos esquecer o sujeito psicológico, individual. Cada aluno e cada professor participante desta pesquisa construíram suas representações a partir da interação com o meio o que implica considerar também sua história pessoal.

Em relação às experiências de aprendizagem e dificuldades vivenciadas não foi encontrada associação significativa entre os professores e alunos " $S$ " (teste exato de Fisher; p-valor=0,091). No entanto, encontramos associação significativa entre os professores e alunos "NS" (teste Qui-Quadrado; p-valor=0,007). Todos os alunos "NS" (100\%) indicaram ter problemas com o conteúdo escolar, enquanto $30 \%$ dos professores não vivenciaram dificuldades e quando a vivenciaram, essas não se relacionaram com os conteúdos escolares.

Comparando os alunos encontramos associação significativa entre os grupos (teste exato de Fisher; p-valor<0,001). Todos os alunos "NS" (100\%) indicaram ter dificuldades com o conteúdo escolar enquanto $60 \%$ dos alunos "S"afirmaram não ter vivenciado. Dos professores que vivenciaram dificuldades para aprender $(60 \%)$, descreveram essa experiência relativa aos conteúdos escolares específicos: "não conseguia resolver frações", "fui reprovada por causa da matemática", "tive dificuldade com química no colegial, precisei de aula particular", "não aprendia inglês, tive muita dificuldade". Os demais (10\%) relacionaram suas dificuldades com outros aspectos como: "aprender a cozinhar", "lidar com a rotina do casamento", "cuidar da casa e dos filhos".

A conseqüência das próprias dificuldades poderia ser um elemento a favorecer a receptividade do professor, como forma positiva de acolhimento para com seu aluno que também enfrenta situações semelhantes. Para Furlani (2004) isso provocaria alterações no olhar sobre o ensino, a educação e sobre si mesmo. Nesse sentido, $60 \%$ de nossa amostra de professores seriam beneficiados por esse olhar.

Por outro lado, os alunos (100\% dos "NS" e $40 \%$ dos "S") afirmaram que os conteúdos e tarefas escolares são difíceis para aprender, destacando a necessidade de mais tempo ou de maiores explicações do professor. No entanto, $60 \%$ 
dos estudantes "S" afirmaram não encontrar dificuldades, pois quando o professor ensina algo novo, no início pode parecer difícil, mas essa aparente dificuldade é superada, o que não acontece com os alunos "NS". Nas palavras desses últimos: "eu me esforço, presto atenção", "preciso de mais tempo para fazer a tarefa", "às vezes a professora precisa explicar de novo". Podemos dizer que os alunos com baixo desempenho acadêmico parecem estar tão mergulhados no esforço para atingir os objetivos dos conteúdos escolares, acabando por não perceber a dinâmica da aprendizagem. Esses alunos relacionam o valor das tarefas escolares com o valor que o professor Ihe atribui.

Em relação aos locais apontados como sendo referência para a aprendizagem, temos uma representação bem diferente entre professores e alunos. $\mathrm{Na}$ análise estatística encontramos associação significativa entre os professores e alunos "NS" (teste Qui-Quadrado; $p$-valor=0,001) e entre professores e alunos "S" (teste Qui-Quadrado; p-valor<0,001). Apenas $20 \%$ dos professores apontaram a escola como local de referência para a aprendizagem enquanto todos os alunos "S" (100\%) e 65\% dos "NS" a indicaram. Esse dado chama atenção, pois para os docentes a família é responsável pela aprendizagem e pela não aprendizagem dos alunos enquanto esses últimos consideram a escola como local de referência para se aprender. Encontramos associação significativa ao comparar alunos "NS" e "S" em relação à mesma categoria (teste exato de Fisher; p-valor $=0,008$ ). Todos os alunos "S" $(100 \%)$ indicaram a escola enquanto 35\% dos "NS" apontaram outros ambientes como local de referência para a aprendizagem.

Analisando a representação do ambiente de aprendizagem e pessoas significativas, $45 \%$ dos professores apontam à família como responsável pela educação e transmissão de valores, $35 \%$ consideram que qualquer pessoa, como o grupo de amigos ou a igreja pode ser referencial para a aprendizagem dos alunos. Apenas $20 \%$ indicam a escola como principal lugar de acesso aos conteúdos específicos, para esses "a escola é responsável pelo conteúdo formal", "ensina conteúdos necessários para que o indivíduo se torne apto ao trabalho".

Acreditamos que para os alunos a escola seja o local designado para aprender porque socialmente ela é valorizada e legitima o conhecimento, possibilitando a oportunidade de crescimento pessoal e profissional. Já os professores pensam apenas nos conteúdos formais, delegando à família o ensino e a manutenção de conteúdos comportamentais e valorativos. Há, portanto, uma representação difusa entre professores e alunos. Nessa perspectiva, a escola é garantia de acesso aos conteúdos formais, no entanto, os demais conhecimentos devem "vir de casa".

Ao analisar a representação de professores e alunos sobre alunos com dificuldades para aprender, encontramos associação significativa entre professores e alunos " $S$ " (teste exato de Fisher; $p$-valor=0,011). A maioria dos alunos "S" $(90 \%)$ aponta como característica desse aluno o desinteresse e apenas $10 \%$ consideram a existência de uma doença. Para $50 \%$ dos professores os alunos com dificuldades para aprender são desinteressados, outros 20\% apontam uma doença ou problema orgânico e $30 \%$ indicam outras características, como a falta de apoio familiar.

Esses dados revelam que a dificuldade do aluno é compreendida como um problema da criança, de ordem afetiva - como seu desinteresse, a falta de apoio da família, ou orgânico. Torna-se evidente a falta de reflexão do professor sobre a sua prática e o seu trabalho em relação ao desempenho do aluno. Nesse sentido, uma leitura inadequada por parte do professor a respeito de como o aluno lida com o conhecimento pode, segundo Rubinstein (2003), contribuir para explicar em parte o aparecimento da dificuldade de aprendizagem. Isso mostra que os professores não estão conseguindo lidar com as diferenças dentro da sala de aula.

Em síntese, as representações dos professores acerca do desempenho acadêmico bem como sobre as dificuldades de aprendizagem se centram em problemas internos dos alunos, atribuindo às causas da dificuldade, com maior freqüência, a fatores que não dizem respeito a sua atuação.

Comparando professores e alunos "NS" em relação à mesma categoria, não encontramos associação significativa (teste Qui-quadrado; p-valor=0,530) entretanto encontramos associação significativa entre alunos "NS" e "S" (teste Qui-Quadrado; p-valor=0,008). A maioria dos alunos "S" (90\%) aponta para o desinteresse, enquanto $45 \%$ dos alunos "NS" consideram o mesmo. A característica doença foi apontada por $35 \%$ dos alunos "NS", outros $20 \%$ afirmam ser a matéria difícil.

As representações dos alunos ("NS" e "S") sobre crianças com dificuldades para aprender se aproximam. Ambos apontam o desinteresse como principal característica desse grupo, o que também foi descrito pelos professores. Nesse sentido, Castro (2004), destaca que o aluno com dificuldade para aprender, poderá sofrer por possuir auto estima abalada pelas representações de seus professores. Para $10 \%$ dos alunos "S" e $35 \%$ dos "S" uma pessoa pode não aprender porque tem um problema, assim exposto: "tem problema na cabeça, tem doença" "é doente da cabeça", "tem problema do cérebro".

No entanto, comparando os argumentos dos dois grupos, os alunos "NS" (20\%) apontaram outras causas para a não aprendizagem, tais como: não fazer a lição, ter dificuldade com a matéria. Talvez esse grupo consiga ter uma visão mais geral sobre essa problemática por serem integrantes dela.

Em relação à percepção positiva do outro, não foi encontrada associação significativa entre professores e alunos "NS" (teste exato de Fisher; p-valor=0,487) nem entre professores e alunos "S" (teste exato de Fisher; p-valor=1,000). Também não encontramos associação significativa entre os alunos "NS" e "S" em relação à mesma categoria (teste exato de Fisher; p-valor=0,741).

Cabe esclarecer que tanto na categoria percepção positiva quanto negativa, a variável - relacionamento - diz respeito às interações vivenciadas em sala de aula. Enquanto a variável - desempenho - compreende, na visão do professor, o bom desempenho dos alunos e o cumprimento das 
tarefas e, na visão do aluno, a disponibilidade do professor para ensinar com calma e respeitando o tempo de aprendizagem dos estudantes.

Encontramos associação significativa entre os professores e alunos "NS" em relação à percepção negativa do outro (teste exato de Fisher; p-valor=0,014). A maioria dos alunos com baixo desempenho acadêmico (80\%) tiveram uma percepção negativa em relação ao relacionamento com seu professor, enquanto $64 \%$ dos professores apontam para o desempenho e a indisciplina do aluno. Essa categoria implica nas características apontadas pelo professor sobre o mau aluno e na concepção dos alunos sobre o mau professor. $\mathrm{O}$ item desempenho corresponde à maneira de o professor conduzir a aula e ao desinteresse do aluno.

Não foi encontrada associação significativa entre os professores e alunos " $S$ " (teste exato de Fisher; $p$ -valor=0,163) nem entre os alunos "NS" e "S" em relação à mesma categoria (teste exato de Fisher; p-valor=0,480).

Percebemos que as representações dos alunos sobre a percepção do outro, se relacionam diretamente ao aspecto afetivo, ou seja, à maneira como o aluno sente e percebe o tratamento e o comportamento do professor para com ele. Nesse aspecto há uma estreita relação entre as representações dos professores com a de seus alunos.

Os professores ao descreverem o bom aluno direcionam seu olhar para a aprendizagem, focando o desempenho. Entretanto, ao apontar o mau aluno, priorizam o fator afetivo quando destacam a indisciplina e o desinteresse. $O$ mau aluno desperta no professor sentimentos negativos de rejeição, distanciamento e até mesmo raiva. Sentimentos esses também despertados no aluno em relação ao mau professor.

\section{Conclusões}

Nossos resultados revelaram que a aprendizagem é percebida, tanto por professores quanto alunos com baixo e adequado desempenho acadêmico como sinônimo de ausência de erros, ou seja, implica em garantir nota. Esse dado denota uma distorção do seu real objetivo, que seria, a nosso ver, estabelecer relações, experimentar diferentes formas de solucionar problemas, atribuir significado aos conteúdos, ao invés de memorizar respostas e gabaritar uma prova. Comparando as respostas de alunos com baixo desempenho acadêmico e professores, verificamos que ambos valorizam o desempenho frente aos resultados dos exercícios e atividades desenvolvidas e concebem a nota como resultado da aprendizagem. Essa representação é facilmente compreendida porque o conceito obtido pelo aluno define sua vida acadêmica. Se ao final do ano, o estudante consegue alcançar a média, ele é aprovado, caso contrario é reprovado.

Do ponto de vista das relações pedagógicas, podemos inferir nesse grupo de professores a compreensão de aprendizagem como transmissão dos conteúdos e das disciplinas em sentido único, do professor ao aluno. Em outras palavras, alguém ensina e alguém aprende. Nesse sentido, a aprendizagem parece ser um processo individual e não social na medida em que professor e aluno associam o desempenho acadêmico diretamente com o resultado de uma prova, não considerando a evolução desse processo nem os progressos do estudante. Por outro lado, os alunos com bom desempenho acadêmico têm representação diferente de seus professores e colegas com baixo desempenho, pois valorizam o saber fazer as tarefas. A nota para esse grupo (desempenho satisfatório) é fator secundário, talvez isso aconteça porque esses conseguem obter um bom desempenho e não dependem tanto do resultado da prova.

Nossos dados evidenciam que apesar de todo o conhecimento existente na atualidade a respeito dos fatores que participam da aprendizagem, a nota é ainda o que supõe a aprendizagem, como um produto final do que foi trabalhado. $O$ aluno precisa da nota para ser aprovado, independente de seu esforço e participação durante o processo de aprendizagem, e o professor precisa dela para justificar o que foi trabalhado. Nesse sentido, a avaliação continua sendo classificatória, reafirmando uma concepção de educação tradicional, havendo sobrecarga de informações que são veiculadas aos alunos.

Acreditamos que a aprendizagem ocorre além dos muros escolares, contudo, concordamos com a concepção de escola apresentada por Delval (2003); ela é uma instituição com função especializada e não pode ser substituída por outras instituições. Para tal os professores precisam ser capazes de promover situações em que essas capacidades (autonomia, pensamento crítico) sejam trabalhadas e construir um ambiente de aprendizagem adequado. Poucos professores valorizaram a escola enquanto ambiente significativo de aprendizagem, pois quando se reportam evidenciam sua função restrita aos conteúdos formais. Assim, os professores parecem não reconhecer a complexidade da prática educativa ao atribuir a escola apenas a responsabilidade pelos conteúdos específicos. Questões como a ética, a saúde e a disciplina ficaram a cargo da família: "o aluno aprende com a família", "a família ensina os valores e as regras".

Nosso trabalho foi fundamental para compreender as relações entre professores e alunos porque há certas variáveis (motivação, relacionamento, didática, conteúdos) que interferem tanto na aprendizagem quanto no ensino. No entanto, nossas limitações dizem respeito ao estudo da motivação dos alunos e professores, pois este foi um aspecto que não estudamos, e em relação à formação dos professores, não investigamos se estes tiveram acesso a disciplinas em que a afetividade, a moralidade e a ética fossem trabalhadas.

Esta pesquisa permitiu levantar três pontos que merecem ser estudados com maior profundidade, a saber: a formação dos professores, os procedimentos avaliativos nas escolas e políticas públicas de educação que visem o atendimento de alunos que apresentem baixo desempenho acadêmico. Futuras pesquisas nessas áreas certamente serão de grande contribuição para a comunidade científica e para a educação. 


\section{Referências}

Almeida, L. R, \& Placco, V. M. N. S. (2004). As relações interpessoais na formação de professores. São Paulo: Loyola.

André, M. E. D. A. (1991). A pesquisa no cotidiano escolar. Em I. Fazenda, Metodologia da pesquisa educacional. São Paulo: Cortez.

Arruda, A. (2004). Ecologia e desenvolvimento: representações de especialistas em formação. Em M. J. Spink, O conhecimento no cotidiano: as representações sociais na perspectiva da psicologia social (pp. 234-265). São Paulo: Brasiliense.

Bardin, L. (1979). Análise de conteúdo. Lisboa: Edição 70.

Castro, M. L. G. (2004). O olhar psicopedagógico na instituição educacional: o psicopedagogo como agente de inclusão social. Revista Psicopedagogia, 21(65), 108- 116.

Coll, C., \& Miras, M. (2001). A representação mútua professor/aluno e suas repercussões sobre o ensino e a aprendizagem. Em C. Coll, J. Palacios \& A. Marchesi, Desenvolvimento Psicológico e Educação (Vol. 2, pp. 265-275). Porto Alegre: Artmed.

Delval, J. (2003). Propuestas para la escuela. Anais do XX Encontro Nacional de Professores do Proepre. Campinas, SP: Faculdade de Educação da Unicamp.

Dotta, L. T. (2006). Representações sociais do ser professor. São Paulo: Alínea.

Furlani, L. M. T. (2004). A parceria e a aproximação na relação professor - aluno na universidade. Em L. R. Almeida \& V. M. N. S. Placco (Org.), As relações interpessoais na formação de professores (pp. 51-64). São Paulo: Loyola.

Gilly, M. (2001) As representações sociais no campo da educação. Em D. Jodelet (Ed.), As representações sociais (pp. 321-342). Rio de Janeiro: EdUERJ.

Guimarães, S. E. R. (2004). Necessidade de pertencer: um motivo humano fundamental. Em E. Boruchovitch \& J. A. Bzuneck (Orgs.), Aprendizagem: processos psicológicos e contexto social na escola (pp.177-199). Petrópolis, RJ: Vozes.

Jodelet, D. (1995). Folies et représentations sociales. Paris: PUF

Kupfer, M. C. M. (1992). A relação professor - aluno: uma leitura psicanalítica. Dissertação de Mestrado, Instituto de Psicologia, Universidade de São Paulo.
Ladd G. W., Buhs, E. S., \& Troop, W. (2002). Children's interpersonal skills and relationships in school settings: Adaptive signifiance and implications for school-based prevention and intervention programs. Em P. K. Smith, \& C. H. Hart (Eds.), Blackwell Handbook of Children Social Development (pp. 394-415). Massachusetts: Blackwell Publisher.

Moscovici, S. (2005). A representação social da psicanálise. Rio de Janeiro: Zahar.

Moscovici, S. (2010). Representações sociais: investigações em psicologia social. Petrópolis, RJ: Vozes.

Placco, V. M. N. S. (2004). Relações interpessoaiss em sala de aula e desenvolvimento pessoal de aluno e professor. Em L. R. Almeida \& V. M. N. S. Placco (Orgs.), As relações interpessoais na formação de professores. São Paulo: Loyola.

Postic, M. (1989). L'imaginaire dans la relation pédagogique. Paris: PUF.

Rangel, M. (2004). A pesquisa de representação social como forma de enfrentamento de problemas sócio educacionais. São Paulo: Idéias e letras.

Rey, F. G. (1985). Comunicacion, personalidad y desarrollo. Havana: Pueblo y Educacion.

Rubinstein, E. (2003). O estilo de aprendizagem e a queixa escolar: entre o saber e o conhecer. São Paulo: Casa do Psicólogo.

Sadalla, A. M. F. A. (1997). Com a palavra, a professora: suas crenças, suas ações. Tese de Doutorado, Faculdade de Educação, Unicamp, São Paulo.

Santos, A. A. A., Rueda, F. J. M., \& Bartolomeu, D. (2006). Avaliação dos aspectos afetivos envolvidos nas dificuldades de aprendizagem. Em F. F. Sisto \& S. C. Martinelli (Eds.), Afetividade e dificuldades de aprendizagem: uma abordagem psicopedagógica (pp. 93-110) São Paulo: Vetor

Schiele, B., \& Boucher, L. (2001). A exposição científica: uma maneira de representar a ciência. Em D. Jodelet. (Org.), As representações sociais (p. 363-378). Rio de Janeiro: EdUERJ. 
Recebido em: 24/11/11

Reformulado em: $12 / 07 / 12$

$17 / 09 / 12$

Aprovado em: 08/10/12

\section{Sobre as autoras}

Andréia Osti (aosti@rc.unesp.br) e (andreia.osti@gmail.com)

Docente na Universidade Estadual Paulista Júlio de Mesquita Filho - Unesp, Doutora em Educação pela Unicamp,

Endereço: Rua Rodrigues Alves, 559 apto. 61. Bairro Botafogo, Campinas, SP. CEP. 13020-400. e Avenida $24^{\mathrm{a}}$, $\mathrm{n}^{\circ} 1.515$ - Bela Vista, CEP. 13506-900, Rio Claro/SP.

Rosely Palermo Brenelli (roselypb@unicamp.br)

Docente na Faculdade de Educação da Unicamp, Doutora em Educação.

Endereço: Rua Elvino Silva, 30. Vila Brandina, Campinas, SP. CEP. 13092-559.

Trabalho derivado de tese. 
